\title{
Roteiro sacro autoguiado no Centro Histórico de Manaus (AM): uma avaliação do patrimônio cultural edificado
}

\author{
Cláudia Araújo de Menezes Gonçalves Martins \\ Universidade do Estado do Amazonas (UEA), Brasil \\ claudiamenez@gmail.com \\ Edileuza Lobato da Cunba \\ Universidade do Estado do Amazonas (UEA), Brasil \\ ueaedileuza@gmail.com \\ Fernanda de Souza Farias \\ Universidade do Vale do Itajai - Univali, Brasil \\ f3rnandafarias@gmail.com
}

\author{
DOI: https://doi.org/10.18472/cvt.21n3.2021.1913 \\ Redalyc: https://www.redalyc.org/articulo.oa? \\ $\mathrm{id}=115469516001$
}

Recepción: 02 Febrero 2021

Aprobación: 28 Junio 2021

\section{Resumo:}

Esta pesquisa teve como objetivo central analisar as igrejas pertencentes ao roteiro sacro autoguiado do Centro Histórico de Manaus/AM e sua relevância como equipamento turístico da cidade. Para isso, utilizou-se um instrumento de coleta de dados com 14 variáveis distribuídas em três campos de análise: serviços, infraestrutura e patrimônio. Trata-se de um estudo de caso que avaliou as três igrejas do roteiro sacro de Martins (2015) - Igreja Nossa Senhora da Conceição, Igreja Nossa Senhora dos Remédios e Igreja de São Sebastião. Para tanto, partiu-se de uma abordagem qualitativa, utilizando-se da pesquisa exploratória e descritiva no que se refere à finalidade do trabalho. Concluiu-se que, entre as igrejas constituintes do roteiro, a mais bem preparada para o turismo religioso é a Nossa Senhora da Conceição, Catedral Metropolitana de Manaus, pois apresentou melhor infraestrutura e organicidade, segundo nossa análise. Nas demais, verificou-se a necessidade de uma maior aproximação da academia para disponibilizar um produto turístico de qualidade e com continuidade.

Palavras-ChaVE: Turismo religioso, Patrimônio histórico-cultural, Igrejas.

\section{Abstract:}

This research has the main objective analyze the churches belonging to the self - guided sacred route of the Historical Center of Manaus / AM and its relevance as a tourist equipment of the city. For this, a data collection instrument was used with 14 variable data distributed in three areas of analysis: services, infrastructure and equity. This case study evaluated the three churches of the sacred script of Martins (2015), Nossa Senhora da Conceição Church, Nossa Senhora dos Remédios Church and São Sebastião Church. It is an applied research with a qualitative approach. As far as the purpose is characterized as an exploratory and descriptive research. It was concluded that among the churches that compose the script the best prepared is Nossa Senhora da Conceição, which is the Metropolitan Cathedral of Manaus, because it has the best infrastructure. In the others, it still needs a closer approximation of the Academy so that one can have a quality tourist product and with continuity.

KEYWORDS: Religious Tourism, Historical-Cultural Heritage, Churches.

\section{Resumen:}

Esta investigación tuvo como objetivo central analizar las iglesias pertenecientes a la ruta sacro-autoguiada del Centro Histórico de Manaus/AM y su relevancia como herramienta turística de la ciudad. Con este fin, se utilizó un instrumento de recolección de datos con 14 variables distribuidas en tres campos de estudios: servicios, infraestructura y patrimonio. Se trata de un estudio de caso que evaluó las tres iglesias de la ruta sacro de Martins (2015) - Iglesia Nossa Senhora da Conceição, Iglesia Nossa Senhora dos Remédios y Iglesia de São Sebastião. Para eso, se parte de un abordaje cualitativo, utilizándose de la investigación exploratoria y descriptiva en lo que se refiere a la finalidad del trabajo. Se concluye que, entre las iglesias constituyentes de la ruta, la más bien preparada para el turismo religioso es la Nossa Senhora da Conceição, Catedral Metropolitana de Manaus, pues presentó mejor infraestructura y organicidad, según nuestro estudio. En las demás, se verificó la necesidad de una mayor proximidad de la academia para poner a disposición un producto turístico de calidad y con continuidad. 
Palabras Clave: Turismo religioso, Patrimonio historico-cultural, Iglesias.

\section{INTRODUÇão}

A segmentação do turismo está cada vez mais organizada, visando a uma melhoria na comercialização dos produtos de acordo com as motivações ou interesses dos turistas. Nessa perspectiva, este artigo aborda o Turismo Religioso no que tange ao conceito e às necessidades do segmento. Analisa-se ainda a infraestrutura utilizada nesse campo turístico, sendo essa, em sua grande maioria, voltada para os patrimônios históricos edificados, estruturados como produtos turísticos cuja atenção necessária se orienta ao cumprimento de legislações federais e estaduais destinadas à preservação e ao uso dos patrimônios.

Desde os primórdios, a religião é vista como uma crença na qual seus seguidores realizam reuniões (cultos) em diversos lugares (igrejas, templos, terreiros, entre outros), destacando-se pela afeição e veneração a uma força maior - sobrenatural - que, de acordo com os adeptos, está acima de tudo e de todos; sendo superior à humanidade. Nessa direção, observa-se que no mundo inteiro existem lugares famosos procurados por diversas pessoas que, motivadas por sua forte devoção, movimentam importantes setores no país em que se encontram.

Dentro dessa dinâmica, Santos (2002) aponta para alguns exemplos: o Vaticano, onde se encontra a Basílica de São Pedro; Jerusalém, onde aconteceram os momentos mais fortes da vida de Jesus Cristo; o Caminho de Santiago de Compostela, reconhecido pela UNESCO - Organização das Nações Unidas para Educação, Ciência e Cultura como o primeiro itinerário Cultural Europeu da Humanidade; e o Círio de Nazaré, em Belém do Pará, que atrai mais de 2 milhões de fiéis. Tais manifestações movimentam o Turismo Religioso, tornando-o um dos segmentos que mais crescem no mundo, principalmente no Brasil, pois impulsiona a economia, divulga a cultura, incentiva a criação de políticas públicas/sociais e fortalece o destino turístico oferecido à clientela demandada, agregando novos possíveis consumidores desse produto.

Dentro dessa dinâmica, há exemplos como: o Vaticano, onde se encontra a Basílica de São Pedro; Jerusalém, onde aconteceram os momentos mais fortes da vida de Jesus Cristo; o Caminho de Santiago de Compostela, reconhecido pela UNESCO - Organização das Nações Unidas para Educação, Ciência e Cultura como o primeiro itinerário Cultural Europeu da Humanidade; e o Círio de Nazaré, em Belém do Pará, que atrai mais de 2 milhões de fiéis. Tais manifestações movimentam o Turismo Religioso, tornandoo um dos segmentos que mais crescem no mundo, principalmente no Brasil, pois impulsiona a economia, divulga a cultura, incentiva a criação de políticas públicas/sociais e fortalece o destino turístico oferecido à clientela demandada, agregando novos possíveis consumidores desse produto.

Diante desse horizonte promissor, tem-se a cidade de Manaus, metrópole localizada na região Norte do Brasil, capital do Estado do Amazonas, cujo Centro Histórico apresenta capelas e igrejas que detêm grande significado para a sociedade local. Além disso, esses lugares demonstram significância como patrimônio material, evidenciando seu grande potencial de oferta como destino cultural, levando-se em conta a historicidade dessas estruturas e o turismo religioso advindo das manifestações de fé que ocorrem em várias épocas do ano.

O desenvolvimento desta pesquisa foi motivado pela inquietação dos autores no que diz respeito à utilização dos templos sagrados pelos adeptos da religião católica, como um produto dentro da seara do Turismo na cidade de Manaus. Nesse sentido, indagou-se sobre como é feita a organização dos locais, visando ao atendimento das necessidades dos turistas pela ótica da interpretação do patrimônio cultural para visitantes. Apesar da existência do roteiro sacro autoguiado do Centro Histórico de Manaus/AM, não existem estudos ou dados que analisem o referido roteiro enquanto equipamento turístico. A partir disso, estruturou-se o seguinte questionamento: como está sendo feita a utilização desse equipamento turístico e qual a sua relevância para a capital do Amazonas? 
Com base nessas considerações, visando à realização deste trabalho, optou-se por executar e analisar o roteiro sacro autoguiado de Martins (2015), dando destaque para as três Igrejas Católicas do Centro Histórico de Manaus. Dessa maneira, a partir do uso do referido roteiro, visamos reunir sugestóes para o seu incremento como um produto turístico viável e sustentável para o mercado local.

\section{Marco teórico - PATrimônio histórico E CUltural E SUA RELAÇÃo com o Turismo}

Compreende-se que a palavra patrimônio pode adotar diversos sentidos, desde os bens de consumo até os aspectos culturais de uma determinada localidade. Segundo Funari e Pelegrini (2006, p. 10), o termo patrimonium, no latim, se referia a tudo o que pertencia ao pai - pater - ou pater famílias, pai de família. Ainda segundo os autores, os termos continham outros significados, pois tudo o que podia ser legado por testamento era tido como patrimônio. Nesse caso, os bens materiais (escravos, imóveis e animais) e a família (esposa e filhos) eram vistos como elementos que formavam seu bem patrimonial. Desse modo, os antigos romanos tinham por patrimônio tudo aquilo que pudesse ser comercializado, algo com valor significativo pertencente ao proprietário, excluindo assim a maior parte da população.

Para Choay (2006, p. 11), o termo patrimônio é de origem romana e está ligado às estruturas familiares, econômicas e jurídicas de uma sociedade estável, enraizada no espaço e no tempo. Dessa maneira, conforme o autor, o termo deixou de se referir somente às grandes construções que obtiverem valor para aquela determinada sociedade e passou a englobar também outros elementos, tais como as tradições locais, crenças, costumes culinários e demais especificidades que compõem a cultura local.

Ramos e Rodrigues (2017, p. 16) afirmam que:

No século XVII, quando na França, o poder público começou a tomar as primeiras medidas de proteção aos monumentos de valor para a história das nações, o uso de "patrimônio" estendeu-se para os bens protegidos por lei e pela ação de órgãos especialmente constituídos, nomeando o conjunto de bens culturais de uma nação.

Desse modo, o conceito de patrimônio passou a ter como base a identidade cultural de um determinado povoado, mediante o qual era possível conhecer e entender melhor os antepassados de cada sociedade, os costumes e os aspectos existentes nos mais diversos povos e nações.

Hoje, ao pensar em patrimônio, os primeiros elementos a se destacarem são os monumentos que detém valor histórico, a sua bela arquitetura e aspectos culturais de uma sociedade; esses são conhecidos por patrimônio cultural. Entretanto, ignoram-se outros elementos que também o constituem, como as cidades, paisagens naturais, artefatos arqueológicos, entre outros.

Ramos e Rodrigues (2017, p. 17) descrevem que "além de servir para o conhecimento do passado, a preservação da cultura serve também para lembrar e ampliar ao homem o sentimento de pertencimento àquele lugar e àquela sociedade”. Por essa razão, ressalta-se a necessidade da preservação dos remanescentes materiais existentes em qualquer âmbito, podendo ocorrer também por outros meios, através das mais diversas formas de expressões - idiomas, dialetos, linguagens, documentos, imagens, manifestações religiosas, artísticas, áreas urbanas ou naturais, entre outros, capazes de transmitir a cultura de uma geração a outra.

De acordo com a Fundação do Patrimônio Histórico e Artístico de Pernambuco (FUNDARPE), são exemplos de patrimônio cultural: sítios arqueológicos, cidades históricas, monumentos, obras de engenharia, castelos, palácios, igrejas, santuários e cidades santas, cemitérios, teatros, museus, festivais, meios de transportes. Inclui-se também as ruínas de cidades históricas, fortes e fortalezas, cidades com traçados planejados, parques de diversões, centros de convenções, carnaval, cassinos, e os centros musicais e de compras (Brasil, 2008).

Conforme o Instituto do Patrimônio Histórico e Artístico Nacional (IPHAN, 2008), patrimônio cultural é classificado em duas categorias: material e imaterial, no qual, o primeiro se refere ao conjunto de bens culturais classificados de acordo com a sua natureza nos quatros Livros de Tombo - em que são registradas 
as obras catalogadas. São eles: arqueológico, paisagístico e etnográfico, histórico, belas artes e artes aplicadas. Pode-se dizer então que o patrimônio material é todo o tipo de bem material possuidor de um valor histórico, a exemplo das estruturas arquitetônicas, esculturas, sítios arqueológicos e pinturas.

Por sua vez, o patrimônio imaterial, segundo o IPHAN (2008), é aquele transmitido por geração e recriado pelas comunidades e grupos de acordo com o seu ambiente e sua história, gerando um sentimento de identidade, continuidade e pertencimento. Sendo assim, pode-se compreender por patrimônio imaterial os costumes e tradições existentes numa cultura: sua arte, crenças, rituais, técnicas culinárias e medicinais; tudo o que se pode repassar e aprender para as novas gerações por meio da convivência cotidiana.

Para Gonzales (2003), os bens materiais e imateriais são indispensáveis para a preservação da identidade histórico-cultural de uma determinada coletividade; em que tanto os bens tangíveis quanto os intangíveis que constituem o patrimônio cultural, são apontados como manifestações ou testemunho significativo da civilização humana. Em 2006, a Organização das Nações Unidas para Educação, Ciência e Cultura (Unesco), publicou um documento referente à preservação do patrimônio cultural imaterial, que passou a incluir: as tradições e expressões orais, expressões artísticas, práticas sociais, ritos e atos festivos, conhecimentos e práticas relacionados à natureza e ao universo, bem como técnicas artesanais tradicionais.

Rössler (2006) publicou um documento referente à preservação do patrimônio cultural imaterial, que passou a incluir: as tradições e expressões orais, expressões artísticas, práticas sociais, ritos e atos festivos, conhecimentos e práticas relacionados à natureza e ao universo, bem como técnicas artesanais tradicionais.

O primeiro órgão brasileiro dedicado à proteção do patrimônio nacional foi o Serviço de Patrimônio Histórico e Artístico Nacional (SPHAN), implementado em 1937, sob o comando de Rodrigo Melo Franco de Andrade (Funari \& Pinsky, 2003). Nesse contexto, Funari e Pelegrini (2006) ressaltam que a criação do SPHAN reforçava a precaução com os bens culturais e históricos, incitando a preocupação com o patrimônio cultural.

Na perspectiva de Funari e Pinsky (2003), o turismo tende a considerar o patrimônio cultural como aquele que se volta em certas atividades propriamente culturais, como as visitas a centros culturais, museus e roteiros temáticos históricos. Entretanto, atualmente o turismo cultural se depara com um relevante dilema, destacado por Meneses (2006, p. 13):

Turismo passa por um momento histórico em que a despeito de ser um dos poucos setores da economia com possibilidades ainda ampliadas de crescimento, se vê em uma encruzilhada definidora de rumos: ou se apresenta como uma proposta econômica de inclusão social - contribuir para novas perspectivas de valorização da vida, do consumo de produtos culturais e de distribuição de renda - ou alia-se a uma economia que exclui parcelas imensas da população da participação na produção - optando por uma proposta de consumo de massa que pouco se preocupa com a sustentabilidade.

O patrimônio cultural vem ganhando maior visibilidade e se apresentando como elemento diferenciador no mercado turístico. A relação entre patrimônio e turismo pode ser muito positiva, por isso devem andar sempre juntos, a fim de gerar rentabilidade por meio da utilização sustentável do Turismo. Além disso, proporciona a conservação do patrimônio e a preservação dele como grande influência na manutenção das raízes culturais em diversas regióes do mundo, resgatando o sentimento de patrimônio da população local. Nesse sentido, para Bussons et al (2005, p. 4), "o turismo aparece como uma força motivadora para a preservação do patrimônio ao se considerar que as perspectivas de retorno financeiro através da sua exploração estimulam os investimentos para a restauração e conservação dos bens".

Ressalta-se o quão importante é a integração de todos os habitantes da região onde a atividade turística está sendo inserida e praticada, pois a participação comunitária, além de beneficiar diretamente a economia local, auxiliará o fortalecimento da atratividade da comunidade perante o turista. Compreende-se que os bens culturais podem instituir notáveis elementos de atração turística para uma determinada localidade, ou seja, faz-se necessário pensar em formas diferentes de planejamento participativo em que o bem histórico-cultural 
se torna elemento de construção dinâmica, propiciando inclusão identitária e social de quem participa ativamente desta atividade.

Diante disso, para que os bens históricos sejam utilizados de forma adequada pelo trade turístico, é fundamental a criação de políticas que envolvam toda a administração local e a população nativa da região, visando não somente à questão econômica, mas agregando o real significado da preservação de um patrimônio. Esse tem o papel realizar a continuidade cultural e de ser a principal ligação existente entre o passado e o presente.

Dentro deste contexto, Barretto (2000) afirma que a recriação de espaços revitalizados é um dos fatores que podem desencadear o processo de identificação do cidadão com a sua história e cultura. Dessa forma, é possível avivar o sentimento de pertencimento do homem sobre sua cultura, costumes e tradições, interligando-o ao seu antepassado com o estado contemporâneo.

\subsection{Turismo Religioso}

O turismo vem adquirindo grande espaço na economia mundial, impulsionado pelos elevados níveis de renda, pela criação de novos destinos e pelo interesse dos setores público e privado no seu desenvolvimento (Flores et al, 2012). Na mesma linha, Dechandt (2011) afirma que, no Brasil, o Turismo é concebido como uma atividade econômica cujo potencial para gerar receitas financeiras é muito significativo.

Ressalta-se que, por ser uma atividade de abrangente área de atuação e estando presente em quase todos os setores da economia, faz-se necessário, para a melhor compreensão desse fenômeno, organizar sua segmentação por tipos. Nesse caso, destacam-se os turismos: de lazer, de eventos, desportivos, rural, de saúde, de aventura, gastronômicos, religiosos, entre outros.

Segundo o Ministério do Turismo (2017), o turismo religioso representa mais de 3\% do turismo nacional e movimenta em torno de 15 bilhões de reais anualmente. Evidenciando sua importância para a economia nacional, constata-se que essa modalidade de deslocamento vem se destacando entre as demais.

Este segmento do turismo se efetiva quando o motivo principal do deslocamento das pessoas é participar de eventos de natureza religiosa. Durante a viagem, pode surgir o interesse por diferentes manifestações culturais, mas o objetivo principal dos turistas sempre será a curiosidade pela atividade religiosa específica, tais como peregrinações, romarias, visitas a espaços, festas, espetáculos, entre outros (Dias \& Silveira, 2003).

No meio acadêmico, há uma indefinição a respeito da conceituação de turismo em relação à religião, tendo em vista que essa pode ser confundida com espiritualidade. Pesquisadores afirmam que essa definição depende de cada um, e, diante desse impasse, muitos estudiosos têm argumentado que as atividades espirituais têm paralelos estreitos com a religião, possuindo elevado significado pessoal para muitas pessoas. Nesse contexto, Dann e Cohen (1996) sugerem que as viagens turísticas dessa natureza poderiam se aproximar das odysseys religiosas. De outro modo, MacCannell (1973, p. 589) argumenta que o turismo absorve "algumas das funções sociais da religião no mundo moderno".

Inserindo-se na mesma discussão, Sharpley e Sundaram (2005) afirmam que o turismo pode ser considerado uma religião, pois é um layout para as pessoas refletirem e cultivarem sua espiritualidade. Por sua vez, Vukonić (1996, p. 162) ressalta que o turismo de fato pode se aproximar bastante da religião, pois, assim como ela, fornece às pessoas com tempo livre "um espaço para a contemplação e o criativo, uma unidade de pensamento e ação", logo, "uma oportunidade para os seres humanos de reconhecer e cultivar suas necessidades espirituais".

Assim como a religião contém rituais simbólicos em períodos fixos, o turismo é um ritual social que muitas vezes promove um compromisso nas pessoas em intervalos regulares, para marcar uma conjuntura particular em suas vidas (Durkheim, 1912, 1995; Maccannell, 1973; Vukonić, 1996). A fim de explorar o diálogo sobre as construções de tais concepções de espiritualidade, este artigo aborda o conceito de espiritualidade com o conceito de religião. 
Para Christoffoli (2012), o turismo religioso, no Brasil, cresce relacionado à religiosidade do povo brasileiro. $\mathrm{O}$ autor aponta o turismo como uma atividade econômica que se apropria e transforma a religião, assim como torna seus espaços de manifestação objeto de consumo turístico. O autor afirma ainda que os santuários passam a ser espaços explorados, transformando a religiosidade em produto em detrimento da dimensão sagrada.

Num cenário global, o turismo religioso como fenômeno social e econômico tem despertado o interesse de acadêmicos e empresários pela dinamicidade gerada nas comunidades de acolhimento dos visitantes. Os estudantes se concentram na investigação das motivações, interesses e necessidades espirituais ou culturais que os centros religiosos despertam; já as empresas, buscam identificar o impacto econômico e as perspectivas adicionais de renda que os visitantes geram, criando novas oportunidades de negócios e fontes de renda e emprego para os locais visitados e para o seus entornos (Perilla \& Perilla, 2013).

Bone (2015) menciona o Turismo Espiritual se referindo a "retiro" como uma forma única de turismo, diferenciada do turismo de bem-estar ou spa, devido seu foco em ideais espirituais e na experiência turística em que as atividades espirituais e ideologias são praticadas e simbolicamente evidenciadas nos locais de retiro.

Tradicionalmente, a exploração da espiritualidade dentro da pesquisa em turismo tem sido apresentada em torno de uma perspectiva religiosa, e as viagens e a religião buscam compartilhar uma relação estreita no contexto da imagem tradicional. A partir de uma revisão da literatura desse campo, observa-se em primeiro lugar a grande ocorrência de trabalhos que comparam turismo à religião ou peregrinação. Na verdade, os estudiosos têm argumentado que o turismo tem paralelos estreitos com a religião e possui tanto significado pessoal para algumas pessoas quanto a religião possui (Willson, 2016).

De acordo com Dias e Silveira (2003), o turismo religioso é uma viagem em que a fé é o motivo principal, mas que pode traduzir motivos culturais voltados a conhecer outras manifestações religiosas. Dessa forma, o turismo religioso "é aquele empreendido por pessoas que se deslocam por motivações religiosas e/ou para participarem em eventos de caráter religioso. Compreende-se romarias, peregrinações e visitação a espaços, festas, espetáculos e atividades religiosas" (Dias \& Silveira, 2003, p. 17).

No entanto, Oliveira (2004, p. 52) destaca que:

O turismo religioso não é, necessariamente, um turismo feito por religiosos, místicos, santos populares, devotos e sacerdotes/profissionais de qualquer credo ou confissão religiosa. $\mathrm{O}$ adjetivo "religioso" deve ser reconhecido em sua amplitude espiritual e metafísica, embora esteja perigosamente comprometida com a perspectiva cristã - responsável pela sistematização desse significante, no universo do Império Romano e da Igreja Católica. Portanto, a correta definição para esse tipo de turismo encontra-se num exercício aproximativo. Tal atividade trata-se de um fazer turístico capaz de manifestar algum dado de religiosidade. E é exatamente na religiosidade - no ato popular de professar o sistema de crenças chamado de Religião que o turismo religioso pode ser comparado às peregrinações e romarias aos lugares sagrados, em momentos também sagrados.

Depois deste arcabouço teórico, pode-se dizer que a atividade do Turismo Religioso no mundo ainda está em crescimento, e, nesse caso, a principal motivação consiste nas convicções e crenças dos povos que buscam vivenciar experiências de fé em lugares consagrados pelas inúmeras tradições religiosas.

\section{Metodologia}

Este estudo, de abordagem qualitativa, teve como objetivo central analisar as igrejas pertencentes ao roteiro sacro autoguiado do Centro Histórico de Manaus/AM e sua relevância como equipamento turístico da cidade. Nesse caso, compreendemos que, "na abordagem qualitativa, a pesquisa tem o ambiente como fonte direta dos dados. O pesquisador mantém contato direto com o ambiente e o objeto de estudo em questão" (Prodanov \& Freitas, 2013, p. 70). 
A fim de investigar de maneira mais próxima e descrever os dados observados sobre o objeto estudado, esta pesquisa caracterizou-se como exploratória e descritiva. Para Leal (2011), a pesquisa exploratória está diretamente relacionada a estudos com pouco ou nenhum conhecimento sobre o tema. Já a pesquisa descritiva objetiva obter informações sobre "um fenômeno ou sobre determinada população e à descrição de suas características; também se refere ao estabelecimento de relações entre variáveis” (Leal, 2011, p. 32).

Do ponto de vista técnico, trata-se de uma pesquisa aplicada, pois sugere implementações possíveis ao roteiro sacro para melhor adequação ao equipamento turístico da cidade. Prodanov e Freitas (2013, p. 51) explicam que a pesquisa aplicada "objetiva gerar conhecimentos para aplicação prática dirigidos à solução de problemas específicos".

Mediante a definição dos parâmetros metodológicos, a pesquisa ocorreu, basicamente, em duas etapas. A primeira se referiu a todo o levantamento de dados necessários para a construção do embasamento teórico do trabalho e para o desenvolvimento do instrumento que deu suporte à coleta de dados. Para tanto, utilizou-se a pesquisa bibliográfica e a documental como procedimentos técnicos de pesquisa. Gil (2008, p. 50) afirma que a "pesquisa bibliográfica é desenvolvida a partir de material já elaborado, constituído principalmente de livros e artigos científicos". Esse procedimento "faz parte de toda e qualquer pesquisa, tanto nas etapas iniciais - escolha do tema e formulação do problema -, como ao longo de seu desenvolvimento" (Leal, 2011, p. 39).

A segunda etapa da pesquisa, denominada de pesquisa documental, foi similar à pesquisa bibliográfica, diferenciando-se pela natureza das fontes consultadas. Tal tipo de pesquisa é reconhecida por tratar de materiais que não receberam tratamento analítico, isto é, são dados mais brutos, tais como: documentos oficiais, cartas, fotografias, reportagens de jornal, filmes, etc. (Gil, 2008).

Um dos principais resultados da pesquisa bibliográfica foi a formulação do material utilizado para o levantamento dos dados, representado pelo Quadro 01.

Quadro 01 - Variáveis utilizadas para a coleta e análise dos dados

Quadro 01 - Variáveis utilizadas para a coleta e análise dos dados

\begin{tabular}{|c|c|c|}
\hline Construtos & Variáveis & Autor (ano) \\
\hline \multirow{6}{*}{ Serviços } & $\begin{array}{l}\text { Participação da comunidade local na } \\
\text { visitação }\end{array}$ & \multirow{14}{*}{$\begin{array}{l}\text { Murta e Albano } \\
(2002)\end{array}$} \\
\hline & Guias durante as visitas & \\
\hline & Centro de informação para visitantes & \\
\hline & $\begin{array}{l}\text { Atendimento ao público e mercados } \\
\text { específicos }\end{array}$ & \\
\hline & $\begin{array}{l}\text { Eventos ejou festivais para promoção da } \\
\text { Igreja }\end{array}$ & \\
\hline & Gastronomia local evidente & \\
\hline \multirow{4}{*}{ Infraestrutura } & $\begin{array}{l}\text { Atendimento às necessidades especiais de } \\
\text { acessibilidade }\end{array}$ & \\
\hline & Recursos de fauna e flora evidenciados & \\
\hline & $\begin{array}{l}\text { Meios animados de exibição com recursos } \\
\text { mecânicos e eletroeletrônicos }\end{array}$ & \\
\hline & Meios estáticos de comunicação e exibição & \\
\hline \multirow{4}{*}{ Patrimônio } & Reconstrução da história para apreciação & \\
\hline & $\begin{array}{l}\text { Presença de objetos para lembrança de } \\
\text { experiência do bem patrimonial }\end{array}$ & \\
\hline & Modelos e reconstruções & \\
\hline & Objetos e documentos fixos e protegidos & \\
\hline
\end{tabular}

Elaborado pelas autoras (2021)

Fonte: Elaborado pelas autoras (2021).

As variáveis do Quadro 01 foram a base do instrumento de dados desenvolvido para a realização da segunda etapa da pesquisa, que consistiu em todo o processo de coleta de dados em campo. Nessa direção, realizou- 
se o levantamento de campo, tendo como objeto de estudo o patrimônio cultural encontrado no Centro Histórico de Manaus/AM: as Igrejas Nossa Senhora da Conceição, Nossa Senhora dos Remédios e Igreja de São Sebastião. Essas três compõem o Roteiro Sacro autoguiado de Martins (2015).

Assim, destaca-se um estudo de caso, entendido aqui como: o estudo "circunscrito a uma ou poucas unidades, entendidas essas como pessoa, família, produto, empresa, órgão público, comunidade ou mesmo país" (Vergara, 2010, p. 44). Além disso, outro procedimento técnico utilizado neste estudo, foi a pesquisa de campo, considerando-se a visitação in loco nas igrejas indicadas no roteiro. Segundo Vergara (2010, p. 43), a pesquisa de campo é uma "investigação empírica realizada no local onde ocorre ou ocorreu um fenômeno ou que dispõe de elementos para explicá-lo. Pode incluir entrevistas, aplicação de questionários, testes e observação participante ou não".

Nas igrejas, foi utilizada a observação como principal técnica para o levantamento dos dados, constituindose como "elemento fundamental para a pesquisa. [...] sendo na fase de coleta de dados que o seu papel se torna mais evidente” (Gil, 2008, p. 100). Além da observação, foram feitas entrevistas semiestruturadas a fim de sanar as dúvidas ainda restantes. Nesse contexto, de acordo com Leal (2011), a entrevista possibilita uma relação mais estreita entre pesquisador e sujeito e, a opção de utilizar questões abertas possibilita ao pesquisador "ampla flexibilidade para exploração mais completa das informações desejadas" (Leal, 2011, p. 53).

Como forma de seleção dos sujeitos da investigação, utilizou-se a técnica de amostragem não probabilística por conveniência, que consiste na escolha dos elementos (sujeitos) que o pesquisador tem acesso. Geralmente esse tipo de amostragem é utilizado em estudos exploratórios ou qualitativos (Prodanov \& Freitas, 2013).

Quanto à análise dos dados coletados, utilizou-se a Análise de Conteúdo que, conforme Moraes (1999, p. 2), "consiste em uma metodologia de pesquisa utilizada para descrever e interpretar o conteúdo de toda classe de documentos e textos".

\subsection{Caracterização do objeto}

Os objetos de estudo desta pesquisa encontram-se no Centro Histórico de Manaus, campo onde se concentra a maior parte das construções históricas do período áureo formador da rica cultura manauara. As construções advindas desse período possuem estrutura e arquitetura únicas, com a maior parte dos materiais sendo trazidos de diversos lugares do mundo. E entre as tantas edificações, destacam-se a Igreja Nossa Senhora da Conceição (Matriz), a Igreja Nossa Senhora dos Remédios e a Igreja São Sebastião, as quais possuem papel efetivo na construção histórica da cidade de Manaus.

A Igreja de Nossa Senhora da Conceição, que é um dos monumentos mais antigos da cidade, tem sua história ligada à ordem dos religiosos carmelitas, que construíram a capela em 1695, nas proximidades da fortaleza São José da Barra do Rio Negro. A igreja Matriz compõe o Conjunto Arquitetônico e Ambiental do Porto de Manaus e da Praça 15 de Novembro. Em 1950, foi considerada Monumento Histórico pela lei n. ${ }^{\circ} 873$, de 30/12/1950, e Tombada pelo Governo do Estado pelo Decreto n. ${ }^{\circ} 11.039$, de 12/04/1988 (AMAZONAS, 1988), na gestão do governador Amazonino Mendes.

A Igreja Nossa Senhora dos Remédios, construída no local de um antigo cemitério indígena, em 1818, situa-se na Rua Miranda Leão, e foi Tombada pelo Governo do Estado por intermédio do Decreto n. ${ }^{\circ} 11.037$, de 12/04/1988, publicado no Diário Oficial em 14/04/1988. (AMAZONAS, 1988). A igreja é reconhecida pelo dia de homenagem à santa Nossa Senhora dos Remédios, 08 de setembro, data na qual se realizam missas e uma procissão pelos arredores da capela, acompanhada por muitos de seus devotos.

A Igreja de São Sebastião, diferentemente das outras, destaca-se pela arquitetura neoclássica e medievalista. Seu tombamento foi realizado pelo então Governador do Estado do Amazonas, Amazonino Mendes, mediante o Decreto n. ${ }^{\circ} 11.038$, de 12/04/1988, sendo publicado no dia 14/04/1988 no Diário Oficial 
do Estado do Amazonas (Decreto $\mathrm{n}^{\circ}$ 11.038, de 12 de abril tomba a Igreja de São Sebastião, 1988) (AMAZONAS, 1988)

$\mathrm{Na}$ Figura 01 é possível visualizar a localização das três Igrejas no Centro Histórico de Manaus e as coordenadas para a realização do roteiro sacro desenvolvido por Martins (2015).

Figura 01 - Igrejas do Roteiro Sacro Autoguiado do Centro Histórico de Manaus

\section{Roteiro Sacro Autoguiado pelo Centro Histórico de Manaus - A pé}

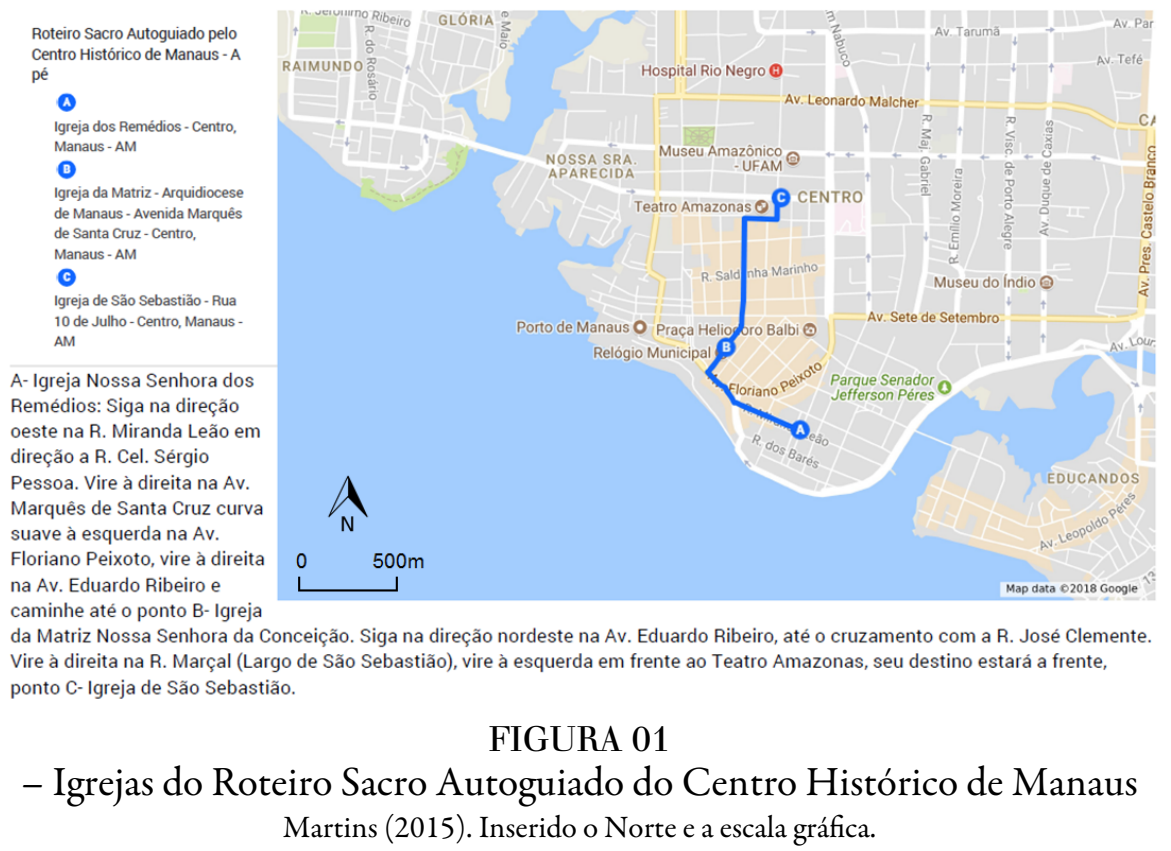

Fonte: Martins (2015). Inserido o Norte e a escala gráfica.

\section{Resultados}

A pesquisa de campo foi realizada com o intuito de aplicar in loco o instrumento de coleta de dados verificando aspectos sobre os serviços oferecidos, a infraestrutura e os aspectos do patrimônio cultural. No Quadro 02, estão dispostas todas as variáveis analisadas e a existência delas em cada uma das igrejas estudadas.

Quadro 02 - Aspectos analisados em cada uma das três Igrejas estudadas 
QUADRO 02

Aspectos analisados em cada uma das três Igrejas estudadas

\begin{tabular}{|c|c|c|c|c|}
\hline \multicolumn{2}{|l|}{ IGREJAS ANALISADAS } & \multirow{2}{*}{$\begin{array}{l}\begin{array}{l}\text { Nossa } \\
\text { Senhora } \\
\text { da } \\
\text { Conceição }\end{array} \\
\mathrm{x}\end{array}$} & \multirow[t]{2}{*}{$\begin{array}{l}\text { São } \\
\text { Sebastião }\end{array}$} & \multirow{2}{*}{$\begin{array}{l}\text { Nossa } \\
\text { Senhora } \\
\text { dos } \\
\text { Remédios }\end{array}$} \\
\hline \multirow{14}{*}{ VARIÁVEIS ANALISADAS } & $\begin{array}{l}\text { 1. Atendimento às necessidades } \\
\text { especiais de acessibilidade }\end{array}$ & & & \\
\hline & $\begin{array}{l}2 . \\
\text { visitação }\end{array}$ & $\mathrm{x}$ & $\mathrm{x}$ & $\mathrm{X}$ \\
\hline & $\begin{array}{l}\text { 3. Atendimento ao público e } \\
\text { mercados específicos }\end{array}$ & $\mathrm{x}$ & $\mathrm{X}$ & $\mathrm{X}$ \\
\hline & $\begin{array}{l}4 . \quad \text { Eventos e/ou festivais para } \\
\text { promoção da Igreja }\end{array}$ & $\mathrm{X}$ & $\mathrm{X}$ & $\mathrm{X}$ \\
\hline & $\begin{array}{l}5 . \quad \text { Centro de informação para } \\
\text { visitantes }\end{array}$ & $\mathrm{X}$ & $\mathrm{X}$ & $\mathrm{X}$ \\
\hline & 6. Guias durante as visitas & $\mathrm{X}$ & $\mathrm{X}$ & $\mathrm{X}$ \\
\hline & $\begin{array}{l}7 . \\
\text { exibição }\end{array}$ & $\mathrm{X}$ & $\mathrm{X}$ & \\
\hline & $\begin{array}{l}8 . \quad \text { Objetos e documentos fixose } \\
\text { protegidos }\end{array}$ & $\mathrm{x}$ & $\mathrm{X}$ & \\
\hline & 9. Modelos e reconstruções & $\mathrm{X}$ & & \\
\hline & $\begin{array}{l}\text { 10. Meios animados de exibição com } \\
\text { recursos mecânicos e eletroeletrônicos }\end{array}$ & $\mathrm{X}$ & & \\
\hline & $\begin{array}{l}\text { 11. Recursos de fauna e flora } \\
\text { evidenciados }\end{array}$ & $\mathrm{X}$ & $\mathrm{X}$ & $\mathrm{X}$ \\
\hline & 12. Gastronomia local evidente & & $\mathrm{X}$ & \\
\hline & $\begin{array}{l}\text { 13. Presença de objetos para } \\
\text { lembrança de experiência do bem } \\
\text { patrimonial }\end{array}$ & $\mathrm{X}$ & & \\
\hline & $\begin{array}{l}14 . \quad \text { Reconstrução da história para } \\
\text { apreciação }\end{array}$ & $\mathrm{x}$ & & \\
\hline
\end{tabular}

Elaborado pelas autoras (2021).

Fonte: Elaborado pelas autoras (2021).

Analisando os locais de pesquisa, apesar da existência de itens comuns nas três igrejas, apenas uma delas está devidamente preparada para receber os visitantes de forma satisfatória, se considerarmos o uso do patrimônio histórico para fins de conhecimento do turismo religioso no Centro Histórico de Manaus. Com base nisso, descreve-se cada um dos itens analisados, a seguir

a) Item 1 - Atendimento às necessidades especiais de acessibilidade

Somente a Igreja Nossa Senhora da Conceição - Catedral Metropolitana - atende a este item, pois realizou adaptações para que sua entrada apresentasse maior acessibilidade para os cadeirantes, além de demonstrar facilidade de acesso durante todo o percurso interno do ambiente.

Nas igrejas São Sebastião e Nossa Senhora dos Remédios, nenhuma adaptação foi feita visando à acessibilidade dos frequentadores e/ou dos visitantes.

b) Item 2 - Participação da comunidade na visitação

Como as três igrejas estão localizadas no Centro Histórico de Manaus, foi informado que a comunidade do entorno dos locais é constituída, em sua grande maioria, pelas pessoas que trabalham nas proximidades das igrejas, não sendo necessariamente residentes do bairro. Desse modo, a participação da comunidade local não é rotineira.

c) Item 3 - Atendimento ao público e mercados específicos / Item 6 - Guias durante as visitas

No caso dos itens 3 e 6 , nas três igrejas analisadas, tanto o atendimento ao público, quanto a disponibilidade de guias, devem ser agendados com antecedência para que uma pessoa da comunidade religiosa possa realizar 
a condução dos grupos dentro das igrejas. Sem o aviso prévio, os funcionários, se estiverem disponíveis, fazem o acompanhamento, mas sem muita segurança.

d) Item 4 - Eventos e/ou festivais para promoção da Igreja

Por tradição católica, as igrejas sempre realizam o festejo em honra aos seus padroeiros. Com isso, utilizam os eventos para promover a crença e angariar fundos. No caso da Igreja de Nossa Senhora dos Remédios, o festejo é realizado no dia 08 de setembro, e no dia 06 de outubro realiza-se também o dia da paróquia. No que se refere à Nossa Senhora da Conceição, o festejo é comemorado no dia 08 de dezembro e, por sua vez, o de São Sebastião ocorre no dia 20 de janeiro.

e) Item 5 - Centro de informação para visitantes

Nos três locais, as informações referentes às igrejas são fornecidas pela secretaria da paróquia, o que facilita todo o andamento da rotina das igrejas, horários das missas, bem como a programação diária.

f) Item 7 - Meios estáticos de comunicação e exibição

Somente nas igrejas de Nossa Senhora da Conceição e de São Sebastião verificou-se a disponibilidade de displays com informações sobre as atividades de cada uma.

g) Item 8 - Objetos e documentos fixos e protegidos

$\mathrm{Na}$ igreja de Nossa Senhora da Conceição, há um museu com peças da visita de Sua Santidade, o Papa João Paulo II, além de vestes dos Bispos, relíquias do tempo em que a igreja foi acometida por um grande incêndio, bem como um pedaço do piso original da época das escavações ocorridas na última grande reforma do espaço.

$\mathrm{Na}$ igreja de São Sebastião, existem algumas imagens expostas em locais altos, que facilitam a visualização, mas dificultam o acesso direto. Na Igreja de Nossa Senhora dos Remédios, não há documentos, somente imagens, incluindo a única representação de Nossa Senhora do Líbano da cidade, a qual foi doada pelos libaneses residentes em Manaus. Há outra imagem similar na cidade de São Paulo e ela também é comemorada no seu dia.

h) Item 9 - Modelos e reconstruções

Somente na Igreja de Nossa Senhora da Conceição há cartazes afixados na parede mencionando suas as antigas construções. Nas demais igrejas, não existe nenhuma referência.

i) Item 10 - Meios animados de exibição com recursos mecânicos e eletroeletrônicos

Somente na Igreja de Nossa senhora da Conceição há esse tipo de recurso, o que facilita o acesso a informações sobre a igreja como um todo.

j) Item 11 - Recursos de fauna e flora evidenciados

Nas três igrejas, tanto a fauna quanto a flora são aspectos evidenciados, contribuindo para a experiência positiva nas possíveis visitas que podem ocorrer.

k) Item 12 - Gastronomia local evidente

Somente na Igreja de São Sebastião há a presença da gastronomia local evidente, pois possui uma infraestrutura com restaurantes, barracas e vendedores ambulantes de produtos regionais.

1) Item 13 - Presença de objetos para lembrança de experiência do bem patrimonial / Item 14 Reconstrução da história para apreciação

Somente na Igreja de Nossa Senhora da Conceição foi possível verificar tanto o local para a aquisição de souvenir quanto o espaço para a apreciação da história da igreja, considerando a disponibilidade do seu Museu.

\section{Discussão}

O objetivo principal deste artigo foi analisar o Roteiro Sacro autoguiado que engloba três igrejas católicas do Centro Histórico de Manaus. A partir disso, observou-se o grande valor desses locais para a construção da cultura, o que gerou proposituras para possíveis ações voltadas ao seu incremento como um produto turístico viável e sustentável para o mercado local, podendo ser incluído na rota das cidades do turismo religioso do país. 
Metodologicamente, na primeira fase, realizou-se pesquisa bibliográfica e documental. Na segunda, os dados foram coletados por meio da técnica de entrevistas e observação. Dessa forma, a pesquisa caracterizouse pela abordagem qualitativa, de natureza exploratória e descritiva, com a realização de pesquisa de campo concretizada com os funcionários das igrejas.

Diante dos resultados encontrados, mediante a realização da análise dos dados, foi possível perceber que, dentre as 03 Igrejas pesquisadas, a de Nossa Senhora da Conceição foi aquela que apresentou mais respostas positivas para os questionamentos realizados, seguido da Igreja de São Sebastião e, por fim, da Igreja de Nossa Senhora dos Remédios.

Assim, salienta-se que a Igreja de Nossa Senhora da Conceição está preparada para o acolhimento aos visitantes e/ou turistas no que tange ao uso do patrimônio histórico-cultural como um equipamento turístico. Essa já dispõe de um roteiro autoguiado elaborado em parceria com uma Instituição de Ensino Superior (IES) particular da cidade. Tal ação também despertou interesse de uma turma do curso de Ciências da Computação da Universidade do Estado do Amazonas (UEA), que organizará as informações levantadas neste artigo para elaborar um aplicativo, visando disponibilizá-lo de forma gratuita a todos os visitantes da igreja. Essa atitude da Instituição de Ensino Superior corrobora os estudos de Perilla e Perilla (2013), os quais afirmam que, cada vez mais, o turismo religioso desperta interesse em acadêmicos e empresários, por se tratar de um segmento dinâmico e promissor econômica e socialmente.

Quanto à Igreja de Nossa Senhora dos Remédios, verificou-se grande potencial para ser um local de visitação, pois abriga muitos aspectos históricos que precisam ser devidamente organizados para serem ofertados da melhor forma aos visitantes. Desse modo, a igreja poderá contribuir não só para o roteiro religioso, mas beneficiará a população da cidade no que tange à promoção do sentimento de valorização do cidadão manauara. Barretto (2000) explica que a revitalização de espaços como este atua diretamente no processo de identificação do cidadão com a sua história e cultura.

A Igreja de São Sebastião, por estar ao lado de um ícone do patrimônio histórico-cultural e turístico da cidade de Manaus, o Teatro Amazonas, também possui grande potencial. Contudo, não se apresenta de maneira estruturada para o turismo religioso, atendendo o visitante somente quando é informada com antecedência, o que dificulta a livre visita ao local.

Com o desenvolvimento deste estudo vislumbrou-se a possibilidade de estreitar a relação da comunidade católica com a Escola Superior de Artes e Turismo (ESAT), por meio da contribuição do curso de Turismo, enfatizando o interesse da menionada Universidade em atividades como esta (Perrilla \& Perilla, 2013). Esse suporte acontecerá mediante a organização dos souvenires disponibilizados para comercialização nas igrejas, assim como a participação de alunos para atuarem como condutores de visitantes, em parceria com o estágio supervisionado obrigatório, amparado pelo convênio recém-assinado entre a Arquidiocese de Manaus e a Universidade do Estado do Amazonas (UEA). Esses feitos agregam um novo conceito aos santuários, transformando-os em espaços de manifestação, em objeto de consumo turístico (Christoffoli, 2012).

\section{Considerações Finais}

Após a etapa de coleta de dados e análise dos itens estabelecidos no roteiro da pesquisa, concluiu-se que somente a Igreja de Nossa Senhora da Conceição está preparada para o acolhimento aos visitantes e/ou turistas, no que se refere ao uso do patrimônio histórico-cultural como um equipamento turístico. Contribui para essa constatação o fato de a igreja em questão já possuir um roteiro autoguiado, elaborado em parceria com uma Instituição de Ensino Superior particular da cidade.

A pesquisa teve como limitação a restrição relativa ao horário para o contato com os responsáveis pelas atividades das igrejas. Todavia, por se tratar de uma pesquisa de cunho majoritariamente observacional, esta limitação foi superada a contento. 
Diante do que foi observado, a Igreja de Nossa Senhora dos Remédios tem grande potencial para ser um local de visitação, pois abriga muitos aspectos com importância histórica, entretanto, necessita de uma efetiva organização para oferecer seus evidentes atributos aos visitantes.

A Igreja de São Sebastião, por estar ao lado do Teatro Amazonas, lugar reconhecido mundialmente, possui potencial e certo preparo. No entanto, a burocracia que existe para a visitação do turista ainda é um ponto negativo que não se soma à perspectiva do tipo turismo aqui discutido.

Esse artigo não tem a pretensão de esgotar a investigação sobre o tema e mostrar-se como o único caminho a ser percorrido. Busca, na verdade, ser visto como uma porta para outras discussões, possibilitando aos estudiosos da temática o aprofundamento dentro das suas áreas específicas de pesquisa.

No decorrer do seu desenvolvimento, este estudo despertou o interesse de uma turma do curso de Ciências da Computação da Universidade do Estado do Amazonas, que utilizará as informações levantadas e sistematizadas neste estudo para a construção de um aplicativo. Este será disponibilizado de forma gratuita a todos os visitantes das igrejas analisadas aqui.

Nessa perspectiva, sugere-se que pesquisas futuras desenvolvam trabalhos voltados para os fatores da acessibilidade, não só para os cadeirantes, mas também para pessoas com deficiência visual ou auditiva. Além disso, propõe-se uma compilação das histórias das igrejas de Nossa Senhora dos Remédios, Nossa Senhora da Conceição e de São Sebastião. E, finalmente, aponta-se para a necessidade de capacitação de pessoal especializado para atender aos turistas, bem como divulgação dos produtos pelas igrejas e pelas agências de viagens para seus clientes, sem esquecer a necessária integração do produto com outros oferecidos no entorno das igrejas.

A motivação para o desenvolvimento da pesquisa surgiu do fomento, o qual deve ser também uma função da academia, ao passo que pode oferecer ideias para o desenvolvimento e melhoria dos produtos turísticos de uma localidade.

A motivação para o desenvolvimento da pesquisa surgiu do interesse em fomentar a pesquisa, o qual deve ser também uma função da academia, ao passo que pode oferecer ideias para o desenvolvimento e melhoria dos produtos turísticos de uma localidade.

Assim, o referido trabalho contribui para o incremento da atividade turística na cidade de Manaus, oferecendo um produto para os turistas culturais que podem, ao mesmo tempo, vivenciar a experiência de conhecer edificações históricas e renovar a sua fé.

Para trabalhos futuros, sugere-se um aprofundamento da temática e maior abrangência do lócus da pesquisa, podendo contemplar toda a região norte do Brasil, visto que esta possui um rico patrimônio cultural e uma valorosa tradição religiosa.

\section{RefERÊNCIAS}

AMAZONAS (Estado). Constituição (1988). Decreto no 11.038, de 12 de abril de 1988. Tomba como Monumento Histórico do Estado do Amazonas o bem que específica e dá outras providencias. Tombamento da Igreja de São Sebastião. Manaus, AM: Imprensa Oficial do Amazonas, 14 abr. 1988. n. 0740. Disponível em: https://diario.i mprensaoficial.am.gov.br/portal/visualizacoes/pdf/8500/\#/p:22/e:8500. Acesso em: 09 dez. 2021.

AMAZONAS (Estado). Constituição (1988). Decreto no 11.037, de 12 de abril de 1988. Tomba como Monumento Histórico do Estado do Amazonas o bem que específica e dá outras providencias. Tombamento da Igreja de Nossa Senhora dos Remédios. Manaus, AM: Imprensa Oficial do Amazonas, 14 abr. 1988. n. 0740. Disponível em: https://diario.imprensaoficial.am.gov.br/portal/visualizacoes/pdf/8500/\#/p:22/e:8500. Acesso em: 09 dez. 2021.

AMAZONAS (Estado). Constituição (1988). Decreto no 11.039, de 12 de abril de 1988. Tomba como Monumento Histórico do Estado do Amazonas o bem que específica e dá outras providencias. Tombamento da Igreja de Nossa Senhora da Conceição. Manaus, AM: Imprensa Oficial do Amazonas, 14 abr. 1988. n. 0740. Disponível 
em: https://diario.imprensaoficial.am.gov.br/portal/visualizacoes/pdf/8500/\#/p:22/e:8500. Acesso em: 09 dez. 2021.

Barretto, M. (2000). Turismo e legado cultural: as possibilidades do planejamento. Campinas, SP: Papirus.

Barreto, M. (2000). Turismo e Legado Cultural: as possibilidades do planejamento. Campinas (SP): Papirus.

Bussons, A. M., Hamabata, K. M., \& Gonçalves, P. I. F. (2005). Importância do Turismo para a Preservação do Patrimônio Histórico-cultural. BAHL, Miguel; MARTINS, Rosilene Conceição Rocha; MARTINS, Sérgio Fernandes. O Turismo como Força Transformadora do Mundo Contemporâneo, 1-13.

Brasil. (2008). "Modificação e alteração do sistema de incentivo à cultura. Lei no 13.407, de 14 de março de 2008. Altera o sistema de incentivo à cultura e dá outras providências". Disponível em: http://www.cultura.pe.gov.br/wp-cont ent/uploads/2014/09/LEIS-CONSOLIDADAS-2003-a-2008.pdf. Acesso em 05 set 2018.

Choay, F. (2006). “A alegoria do patrimônio”.Lisboa: Edições 70.

Christoffoli, A. R. (2012). "Turismo e Religiosidade no Brasil: Uma Análise das Interpretaçôes de Teóricos e Autores da Area do Turismo sobre Deslocamento e Consumo em Santuários Católicos”. Tese (Doutorado em Administração e Turismo) - Universidade do Vale do Itajaí, Biguaçu.

Dann, G. M., \& Cohen, E. (1996). Sociology and tourism. The sociology of tourism: theoretical and empirical investigations., 301-314.

Decreto $n^{\circ} 11.038$, de 12 de abril tomba a Igreja de São Sebastião, 1988.

Dechandt, S. G. (2011). "Gestão do Turismo em Territórios de Grande Densidade Religiosa: o caso do Novo México". 2011. Tese (Doutorado em Administração) - Universidade Federal da Bahia, Salvador.

Dias, R.; Silveira, E. (2003). “Turismo Religioso: ensaios e reflexões”. Campinas: Alínea.

Durkheim, E. (1912). La méthode sociologique. Félix Alcan.

Durkheim, E. (1995) Da divisão do trabalho social. São Paulo: Martins.

Flores, L. C. da S.; Cavalcante, L. de S.; Raye. R. L. (2012). "Marketing turístico: Estudo sobre o uso da tecnologia da informação e comunicação nas agências de viagens e turismo de Balneário Camboriú (SC, Brasil)". Revista Brasileira de Pesquisa em Turismo. São Paulo, .(3), pp. 322-339.

Funari, P. P. A.; Pelegrini, S. C. A. (2006). "Patrimônio Histórico e Cultura”. Rio de Janeiro: Jorge Zahar. ed.

Funari, P. P; Pinsky, J. (Orgs.). (2003). “Turismo e Patrimônio cultural”. 3 ed. São Paulo: Contexto.

Gil, A. C. (2008). "Métodos e técnicas de pesquisa social". 6 ed. São Paulo: Atlas.

Gonzales-Varas, I. (2003). Conservación de bienes culturales. Madrid: Cátedra.

IPHAN. (2008) "INSTITUTO DO PATRIMÔNIO HISTÓRICO E ARTÍSTICO NACIONAL". Dicionário IPHAN de patrimônio cultural". Rio de Janeiro: IPHAN, COPEDOC.

Leal, E. J. (2011). "Produção acadêmico-cientifica [recurso eletrônico]: a pesquisa e o ensaio". Itajaí: Universidade do Vale do Itajaí.

Maccannell, D. (1973). Staged authenticity: Arrangements of social space in tourist settings. American Journal os Sociology, 79(3), 589-603.

Martins, C. K. da S. (2015). "Roteiro Sacro Autoguiado pelo Centro Histórico de Manaus". 2015. Trabalho de Conclusão de Curso (Bacharelado em Turismo) - Universidade do Estado do Amazonas, Manaus. 72 p.

Meneses, J. N. C. (2006). "História \& Turismo cultural”. 1. ed., 1 reimp. - Belo Horizonte: Autêntica.

Ministério do Turismo. (2017). "Turismo Movimenta Economia do Pais". Disponível em: http:// www.turismo.gov.br/component/content/article. Acesso em: 28 de julho de 2019.

Moraes, R. (1999). Análise de conteúdo. Revista Educação, Porto Alegre, v. 22, n. 37, p. 7-32.

Murta, S. M.; Albano, C. (orgs). (2002). Interpretar o patrimônio: um exercício do olhar. Belo Horizonte, MG: Ed. UFMG.

Oliveira, C. D. M. de. (2004). "Turismo religioso". São Paulo: Aleph.

Perrilla, S. M. T.; Perilla, N. T. (2013). "Turismo religioso: Fenomeno Sociale Economico". Anuário Turismo y Sociedad, Vol. 15, Noviembre, pp. 237-249. 
Cláudia Araújo de Menezes Gonçalves Martins, et al. Roteiro sacro autoguiado no Centro Histórico d...

Prodanov, C., Freitas, E. C. (2013) "Metodologia da pesquisa cientifica: métodos e técnicas da pesquisa e do trabalho acadêmico". Novo Hamburgo: Feevale.

Ramos, C. M. Q.; Rodrigues, J. M. F. (2017). Turismo e tecnologia: Qualificando a experiência do turista religioso. Revista Rosa dos Ventos, 9(1), 32-48.

Sharpley, R.; Sundaram, P. (2005). Tourism: A sacred journey? The case of ashram tourism, India. International Journal of Tourism Research, 7(3), 161-171.

UNESCO, 2006. Organização das Nações Unidas para Educação, Ciência e Cultura (Unesco) tópico 2

Rössler, Mechtild (2006). World Heritage cultural landscapes: A UNESCO flagship programme 1992 - 2006. Landscape Research, 31(4), 333-353. doi:10.1080/01426390601004210

Vergara, S. C. (2010). "Projetos e relatórios de pesquisa em administração". 12. ed. São Paulo: Atlas.

Vukonić, B. (1996). "Tourism and Religion”. Oxford: Pergamon.

Willson, G. B. (2016). Reconceituar Turismo Espiritual: Considerações Culturais E Uma Comparação Com Turismo Religioso. Turismo, Cultura e Comunicação, Vol. 16, pp.161. 